\title{
Aprendre ensenyant: introducció del paper del mentor a la robòtica educativa
}

\author{
Cristina Vives Ostios, Adrià Marcos Pastor \\ Universitat Rovira i Virgili \\ cristina.vives@estudiants.urv.cat
}

Resum: En aquest article, es proposa una metodologia d'aprenentatge de la robòtica basada en la coresponsabilitat dels alumnes d'ESO com a transmissors del coneixement. Es pretén reforçar els aprenentatges dels estudiants de forma significativa, i donar una gran importància als seus sabers transmetent-los a nens i nenes d'educació infantil. En aquest procés, l'alumne pren un rol de mentor on integra coneixements de robòtica, treballa la competència comunicativa $i$ les habilitats de treball en equip.

Paraules clau: Tecnologia educativa, robòtica educativa, alumne mentor, educació secundària obligatòria, educació infantil.

Abstract: In this work, a learning methodology based on joined students' responsibility for knowledge transmission about robotics is proposed. The aim of this work is to reinforce students' learnings in a significative form by giving special importance to their knowledge due to they have to transmit it to childhood students. In this process, the high school student plays a mentor role where not only learns about robotics but also puts communication and teamwork skills into practice.

Keywords: Educational technology, educational robotics, mentor student, high school education, childhood education.

\section{Introducció}

L'ús de la robòtica com a eina d'ensenyamentaprenentatge va ser impulsada per Seymour Papert als anys seixanta basant-se en la teoria del desenvolupament cognitiu de Piaget. Segons aquesta base, l'alumne construeix el seu aprenentatge a través de la manipulació, l'experimentació i la construcció que ofereix aquesta eina educativa (Miglino, Hautop i Cardaci, 1999).

A més, emmarcat dintre del constructivisme, Papert va desenvolupar un corrent anomenat Construccionisme per remarcar el rol actiu que desenvolupa l'alumne en la construcció de les seves estructures de coneixement (Monsalves, 2011). A partir d'aquest corrent es dedueix que les pràctiques de robòtica realitzades tracten d'aportar contextos reals on es fa necessari mobilitzar un conjunt de sabers teòrics per assolir un objectiu desitjat. Aquesta metodologia, basada en el sistema del laboratori simulat, ensenya als alumnes a treballar seguint el mètode científic que permet assimilar conceptes per mitjà de prediccions sobre el comportament dels mecanismes programats, de la seva manipulació i de lobservació posterior dels resultats (Miglino et alii, 1999).

Segons aquestes bases teòriques, la robòtica educativa es concep com una nova possibilitat d'integrar les TIC al currículum, atès que crea ambients d'aprenentatge motivadors $i$ versàtils 
capaços d'oferir entorns d'aprenentatge interactius on els límits els posa la creativitat de l'alumne (Lau, Tan, Erwin i Petrovic, 1999). A més, permet aplicar coneixements de les àrees de matemàtiques, ciència i tecnologia d'una manera molt més pràctica i visual per als alumnes. Per aquest motiu, molts centres educatius han impulsat aquesta eina a escala curricular en l'etapa d’educació secundaria.

Tot i així, adaptant el material, els beneficis de la robòtica també poden ser extrapolables tant a l'etapa d'educació primària com a la d'infantil. Els infants en aquestes edats veuen aquest recurs com un joc que els ajuda a desenvolupar estratègies de treball en equip, a estructurar el pensament de forma seqüencial i a iniciar-se en el mètode científic (Vives i Marcos, 2013).

\section{Robòtica a educació infantil}

Integrar les noves tecnologies a l'aula d'infantil pot resultar una gran experiència educativa si es realitza a partir d'activitats lúdiques com les que ofereix la robòtica educativa. Un exemple d'aquest tipus d'experiència es dugué a terme a l'Escola de Pràctiques de Tarragona amb infants d'entre 5 i 7 anys durant el curs 2012-2013 (imatge 1).

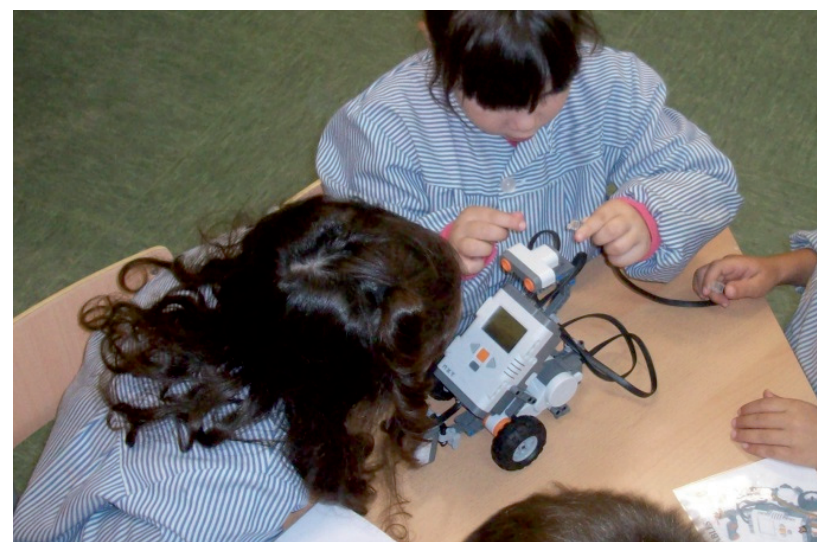

Imatge 1. Alumnes d'EI5 muntant un robot.

L'experiència realitzada va demostrar que aquesta eina ofereix la possibilitat als alumnes de treballar de forma col-laborativa i iniciar-se en el mètode científic, i generar les seves hipòtesis, experimentar amb el robot i comprovar els resultats de la seva programació.

Per poder adaptar el material a aquesta franja d'edat es va generar un seguit de recursos didàc- tics com: unes cartolines amb diferents direccions per estructurar prèviament els passos del robot (imatge 2), uns blocs de programació preprogramats per simplificar les tasques dels alumnes a l'hora de programar el robot i unes instruccions de muntatge amb peces preacoblades per facilitar-ne la construcció.

Considerant l’èxit que va tenir l'experiència, on es va demostrar que els més petits també poden aprendre i gaudir amb aquest material, s'ha apostat continuar l'experiència, però aquest cop fent que alumnes d'educació secundària siguin els encarregats de transmetre els coneixements als alumnes d'educació infantil.

Basant-se en les idees exposades prèviament, s'ha iniciat un estudi de cas on els alumnes de $3 \mathrm{r}$ d'ESO de l'Escola Internacional de Camp (EIC), dins l'assignatura de Tecnologia, reforcen els seus coneixements de robòtica mentre duen a terme un projecte de mentories per presentar aquests coneixements als alumnes d'EI5. Lobjectiu principal d’aquesta experiència és consolidar els coneixements dels alumnes de 3r d'ESO i desenvolupar la competència comunicativa lingüística i les habilitats de treball en equip. Al mateix temps, s'aconsegueix introduir aquesta eina als alumnes d'EI5 perquè s'iniciïn en aquests aprenentatges.

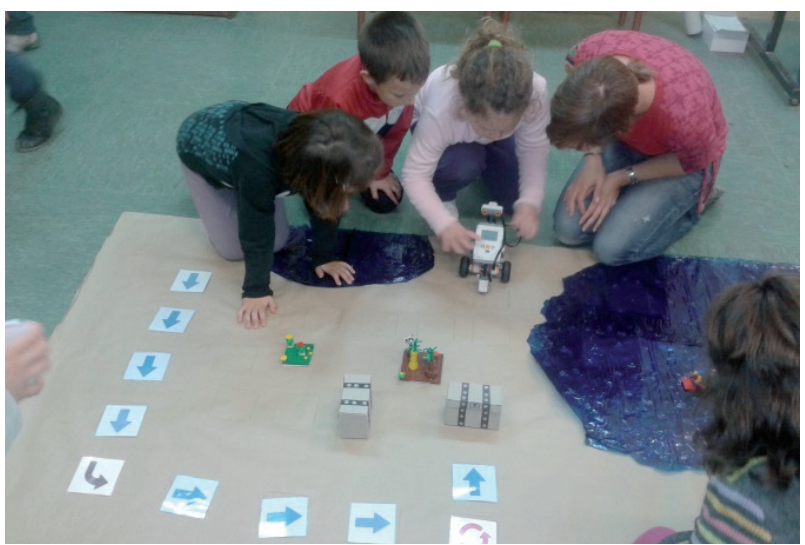

Imatge 2. Alumnes d'EI5 i 1er de primària testejant la programació del robot.

\section{Contextualització}

Per dur a terme aquest projecte, es va seleccionar l'EIC per l'ús innovador en les noves tecnologies i la utilització que en fa com un instrument facilitador d'aprenentatges i de relació entre la comunitat educativa. Aquesta excel-lència en 
l'ús de les noves tecnologies forma part d'un dels quatre eixos fonamentals del projecte educatiu de l'escola. A més, l'EIC aplica un model pedagògic anomenat Sòcrates-Educa amb l'objectiu de fomentar que els alumnes exercitin l'autoaprenentatge, aprenguin a fer de mentors dels seus companys, tinguin capacitat per resoldre conflictes, facin treball cooperatiu, tinguin facilitat per comunicar-se i aportin valor al territori i a la societat.

\section{Descripció de l’experiència}

Durant el primer trimestre, els alumnes de $3 \mathrm{r}$ d'ESO van iniciar-se en l'aprenentatge de la robòtica amb els kits de LEGO Mindstorms ${ }^{\circledast}$ EV3. En aquest període, van construir diferents estructures mecàniques $i$ van aprendre a programar per blocs utilitzant diferents sensors.

A l'inici del segon trimestre, es va presentar la proposta del projecte als alumnes, i se'ls va explicar els objectius i els passos que havien de dur a terme per desenvolupar el conjunt d'adaptacions necessàries per poder presentar aquests continguts als nens i nenes d'EI5.

En concret, la tasca que han realitzat durant el segon trimestre dels alumnes de $3 \mathrm{r}$ d'ESO ha estat:

En primer lloc, desenvolupar una guia d'instruccions de muntatge bàsiques per permetre als infants construir el seu robot utilitzant conjunts de peces acoblades prèviament. Aquestes instruccions s'han realitzat a partir de fotografies capturades amb els iPads que els alumnes han pres de les seves construccions i han editat posteriorment amb l'aplicació Keynote (imatge 3).

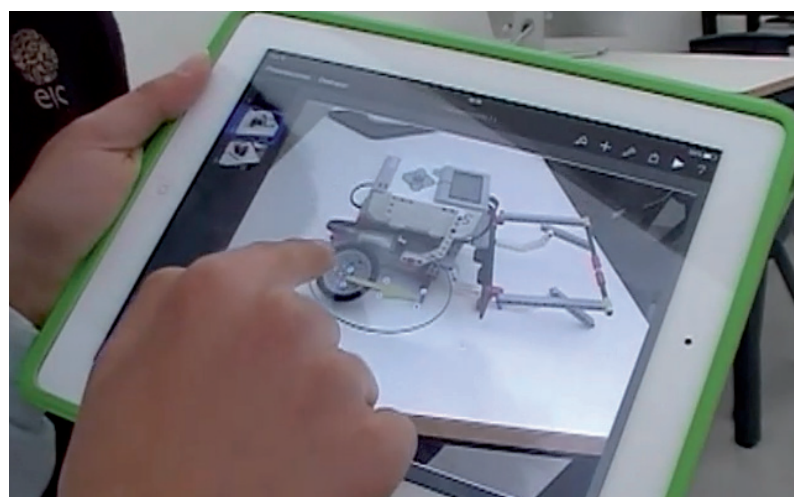

Imatge 3. Alumnes de 3er d'ESO creant una guia de muntatge.
En segon lloc, han programat blocs amb moviments simples (recte, gir dreta, gir esquerra, etc.) associant una imatge a cada bloc perquè els alumnes d'infantil els identifiquin i els puguin utilitzar. Aquest treball s'ha realitzat amb el programari del LEGO Mindstorms EV3 ${ }^{\circledast}$ (imatge 4).

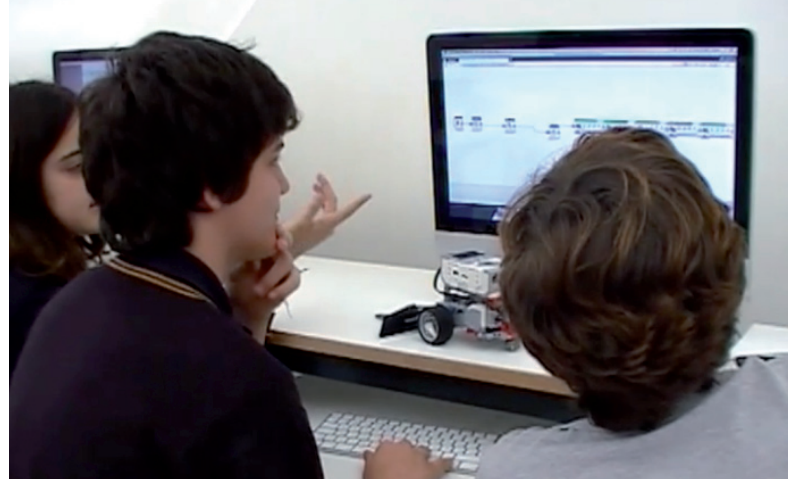

Imatge 4. Alumnes de 3er d'ESO creant blocs de programació.

Finalment, s'ha enregistrat una petita història amb la tècnica de stop-motion utilitzant peces de $\mathrm{LEGO}^{\circ}$. L'stop-motion és una tècnica d'animació que consisteix a reproduir ràpidament un seguit d'imatges per donar un efecte de moviment. Aquesta tasca es va realitzar amb els iPads utilitzant l'aplicació iMotion. L'objectiu d'aquests vídeos és presentar als infants un repte que hauran de solucionar a través de la programació dels seus robots un cop els hagin muntat (imatge 5).

Un cop realitzats tots aquests passos, durant el tercer trimestre els alumnes hauran de dur tot aquest treball a l'aula d'EI5 per exposar els seus coneixements d'una forma entenedora als infants.

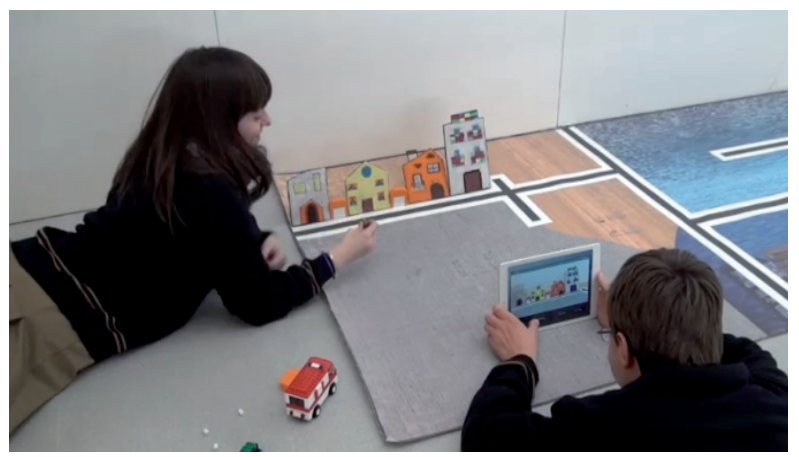

Imatge 5. Alumnes de 3er d'ESO fent una animació $a m b$ stop-motion. 


\section{Avaluació de l'experiència}

Per poder avaluar aquest projecte i dur un seguiment dels aprenentatges dels alumnes, s'han establert diferents mecanismes d'avaluació:

D'una banda, a l'inici del segon trimestre, es va passar un qüestionari a l'alumnat per conèixer la seva percepció amb relació als coneixements de robòtica i a la capacitat de treball en equip i transmissió del coneixement que consideraven tenir. Aquest mateix qüestionari es repetirà en acabar el projecte per valorar si s'ha produit un canvi en la percepció que els alumnes consideren tenir d’ells mateixos.

Per complementar aquesta informació, un cop finalitzat el segon trimestre s'ha realitzat una prova de coneixements on els alumnes han hagut d'explicar els passos que han seguit fins ara per poder realitzar el projecte i quines habilitats han hagut de treballar durant el procés.

D'altra banda, les sessions de robòtica que es realitzin conjuntament amb els alumnes de $3 \mathrm{r}$ d'ESO i EI5 seran enregistrades per poder analitzar a posteriori els intercanvis comunicatius que es duguin a terme amb els alumnes.

Finalment, s'ha dissenyat una entrevista per al professor de l'assignatura de Tecnologia. Aquesta entrevista es realitzarà una vegada acabat el projecte amb l'objectiu de conèixer quina valoració fa el professor de l'experiència.

\section{Primers resultats}

Fins ara, s'han pogut extreure resultats del primer dels dos qüestionaris referent a la percepció dels alumnes pel que fa als continguts de robòtica i a les capacitats necessàries per exposar aquests continguts a l'alumnat d'EI5.

Els resultats d'aquest primer qüestionari mostren que els alumnes es veuen capacitats per dur a terme l'activitat proposada (fig. 1). Sobretot destaquen de forma positiva els valors referents a la construcció d'estructures del robot i la capacitat de treballar de forma col-laborativa amb els companys per assolir els objectius. D'altra banda, els resultats amb un valor més baix són els que fan referència a la programació.

També s'han extret les dades de les competències i habilitats que han hagut de treballar durant el segon trimestre arran de la utilització d'aquesta metodologia d'aprenentatge basada en mentories. Aquestes dades mostren com els alumnes veuen de forma molt positiva tant el fet de treballar en grup com la importància d'exposar els seus coneixements als alumnes d'educació infantil. N'és un exemple el comentari d'una alumna enregistrat a l'examen trimestral, on, amb relació a l'expressió oral, especificava: "A mi em costa molt expressar-me davant de la gent, però, com que són nens més petits que jo, no em fa tanta por equivocar-me i crec que aquest fet majuda-

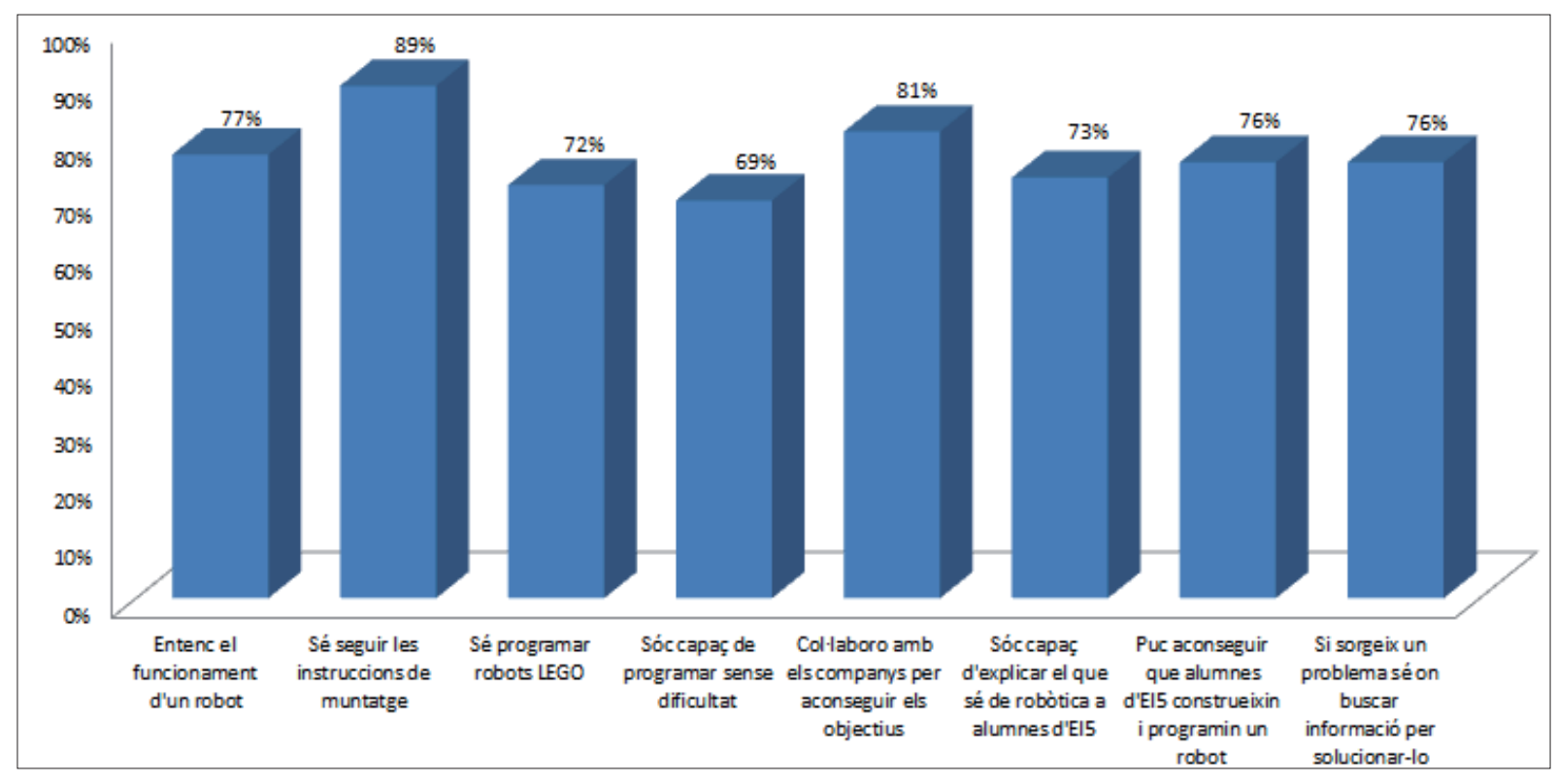

Figura 1. Percepció dels alumnes sobre els seus coneixements i capacitats amb relació al projecte. 
rà a expressar-me millor.” De la mateixa manera, un altre alumne escrivia: "Treballar en grup està molt bé, ja que tots els components del grup tenen idees diferents i les poden posar en comú i un pot aprendre de l'altre."

Per poder plasmar les percepcions de tots els alumnes amb relació a les implicacions que té la realització d’aquest projecte, a continuació es mostra un mapa conceptual amb les idees que han posat de manifest en la prova de coneixements que s'ha realitzat al final de segon trimestre (fig. 2). seves habilitats de gestió de grups. De la mateixa manera, s'ha pogut dur a terme un treball de la competència comunicativa lingüística molt ampli a partir de la comunicació entre el grup, l'exposició de continguts adreçada al grup classe, la pràctica realitzada amb els infants i l'expressió artística amb l'edició d'imatges i vídeos.

Així, doncs, es mostra com la robòtica educativa ofereix noves formes d'integrar el coneixement a partir de la pràctica i l'experimentació. Per aquest motiu, actualment, molts centres estan duent a terme experiències educatives d'èxit

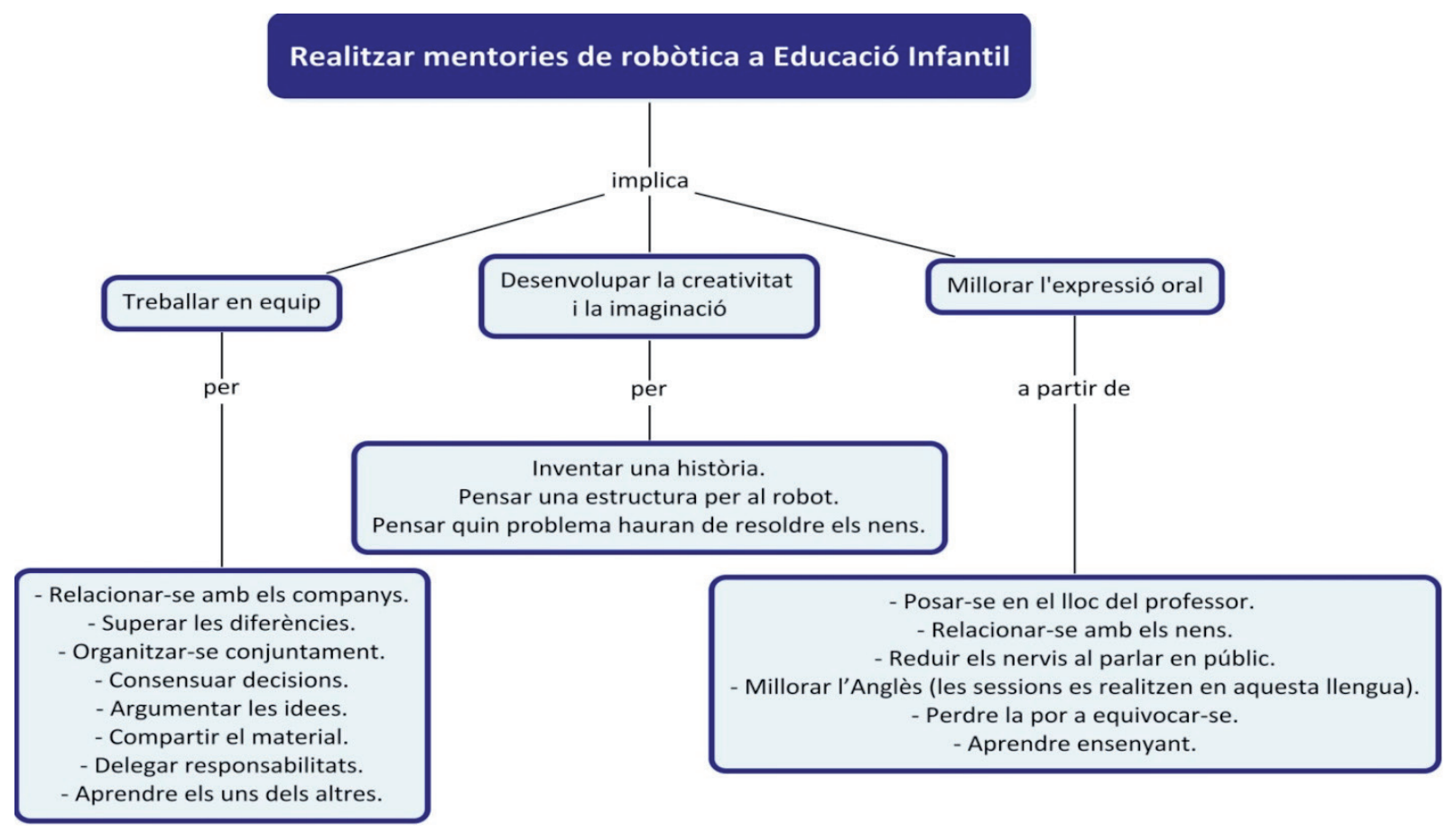

Figura 2. Percepció dels alumnes sobre el seu aprenentatge.

\section{Conclusions}

L'experiència de treballar en grup durant dos trimestres demostra ser tot un repte per als alumnes. Si bé és cert que al qüestionari inicial s’observava que l'alumnat tenia una percepció molt positiva amb relació a les seves habilitats de treball en equip, al llarg de la experiència s'ha anat trobant amb problemes de divergència d'opinions, d’organització i de lideratge. Aquest fet, que s'ha vist reflectit tant en l'observació com en la prova de coneixements, mostra com aquesta metodologia de treball ha implicat que els alumnes desenvolupessin d'una forma pràctica totes les utilitzant la robòtica com a eina d'aprenentatge, ja que gràcies a la seva versatilitat es poden treballar una gran quantitat de competències.

Tot i així, l'ús d'aquestes eines ha d'anar acompanyat d'un model d'ensenyament-aprenentatge on l'alumne prengui un paper actiu en l'aprenentatge, i resolgui els problemes que se li plantegen, de manera que creï el seu coneixement a partir de materials propis.

Dins d'aquest model, el docent, a més de guiar l'alumne, és l'encarregat de plantejar reptes i proposar situacions que generin als alumnes els conflictes cognitius necessaris per aprofundir els 
seus aprenentatges. En aquest sentit, la taxonomia de Bloom per a l'era digital reformulada per Churches (2009) mostra com en la mesura en què els alumnes són capaços de crear el seu material d'ensenyança, treballen en un major grau les habilitats de pensament d'ordre superior que els permeten integrar els seus coneixements.

En conclusió, entenent l'ús de la robòtica educativa com una eina facilitadora en la transmissió dels coneixements, aquest projecte dóna a conèixer la possibilitat d'utilitzar aquesta eina com un recurs educatiu per aprendre a través de la preparació i la realització de mentories tal com s'ha plantejat en etapes d'educació superior per Biswas et alii (2005).

\section{Bibliografia}

Biswas, G.; Leelawong, K.; Schwartz, D.; Vye, N.; The Teachable Agents Group at VANDERBILt (2005). "Learningbyteaching: A new agent paradigm for educational software".
Applied Artificial Intelligence, 19 (3-4), 363392.

Churches, A. (2009). "Taxonomía de Bloom para la era digital". EDUTEKA. Recuperat de <http://www.eduteka.org/TaxonomiaBloomDigital.php $>$.

Lau, K. W.; Tan, H. K.; Erwin, B. T.; Petrovic, P. (1999). "Creative learning in school with LEGO ${ }^{\circledR}$ Programmable Robotics Products". Dins: Frontiers in Educations Conference. San Juan, p. 26-31.

Miglino, O.; Hautop, H.; Cardaci, M. (1999). "Robotics as an educational tool". Journal of Interactive LearningResearch, 10, 25-26.

Monsalves, S. (2011). "Estudio sobre la utilidad de la robótica educativa desde la perspectiva del docente". Revista de Pedagogía, 32, 81-117.

Vives, C.; Marcos, A. (2013). "Experiència d'aprenentatge col-laboratiu de tipus TAC. La robòtica a Educació Infantil". Dins: III Congrés Educació Avui: per un aprenentatge eficaç, eficient $i$ coherent. Tarragona. 